Heatd, P. J., Krogh, N., Mann, S. O., Appleby, J. C., Masson, F. M.

\& Oxfond, A. E. (1953). J. gen. Microbiol. 9, 207-215.

\title{
A Method for Direct Viable Counts of the Facultatively Anaerobic Microflora in the Rumen of a Sheep maintained on a Hay Diet
}

\author{
By P. J. HEALD, * N. KROGH, $†$ S. O. MANN, J. CHRISTINE \\ APPLEBY, FRANCES M. MASSON AND A. E. OXFORD \\ Rowett Research Institute, Bucksburn, Aberdeenshire
}

SUMMARY: By direct viable counts in deep cultures in a basal nutrient agar, consisting of buffered and very highly clarified rumen liquor, supplemented only with vitamin-free acid hydrolysate of casein, tryptophan, a fermentable carbohydrate and agar, the crude wet rumen contents of a hay-fed sheep has been shown to contain a population of $c .10^{8}$ viable and facultatively anaerobic bacteria per g., mostly Gram-positive cocci capable of fermenting a wide range of soluble carbohydrates including starch and inulin but not mannitol. The mannitol-fermenting population is of the order of $10^{6}$ organisms per g., consisting mostly of Gramnegative rods, including coliform bacteria. Addition of reducing substances such as sodium sulphide or mercaptoacetate (thioglycollate) to the basal agar had little or no effect in increasing the counts. An extract of hay made with cleared and sterile rumen liquor did not yield the typical rumen streptococcal flora when counted by this method in raffinose + rumen liquor nutrient agar.

Although most workers with rumen micro-organisms seem to have assumed either that the important fermentative bacteria and protozoa in this very mixed culture must be obligate anaerobes, or that they will not act except under powerful reducing conditions (see, e.g. Hungate (1950); Huhtanen, Rogers \& Gall (1952) and previous papers by Gall and associates on the methods for isolating rumen bacteria; Sijpesteijn \& Elsden (1952) on methods of using washed suspensions of mixed rumen bacteria for fermentation studies), nevertheless there are good reasons for believing that the rumen normally contains a considerable population of facultative anaerobes which are active in fermenting carbohydrates. Thus, by a simple enrichment technique not carried on for more than $18 \mathrm{hr}$., Heald $(1952 a, b)$ isolated numerous pure cultures of coliform bacteria, capable rapidly of fermenting glucose and xylose, from the rumens of hay-fed sheep. MacPherson (1953), in a study of rumen amylolytic bacteria, without any difficulty isolated numerous facultatively anaerobic streptococci, which resembled Strep. bovis in fermentation reactions, from the rumens of both concentrate-fed and hay-fed sheep. These bacteria were absent from the fodder. Sugden \& Oxford (1952) showed that an important and ubiquitous group of sheep's rumen ciliate protozoa, the holotrichs, which are very active in fermenting glucose (Heald \& Oxford, 1953), are not at all exacting in their demands for anaerobic conditions and will

\footnotetext{
* Present address : Biochemical Laboratories, Institute of Psychiatry, Denmark Hill, London, S.E. 5.

$\dagger$ Present address : Norwegian Veterinary College, Oslo, Norway.
} 
flourish in a liquid buffer containing no reducing substances, when no more drastic measures are taken to exclude air than the fitting of a Bunsen valve to the mouth of the culture flask. In the work here described we have endeavoured to count and characterize the viable facultative anaerobic bacteria in the rumen contents of a hay-fed sheep, using for the diluent a medium containing cleared and sterilized rumen liquor supplemented only with a vitamin-free acid hydrolysate of casein, tryptophan, a fermentable sugar and agar. Since the nature of the fermentable sugar greatly influenced the kind and numbers of bacterial colonies which developed, we extended the investigation to include the whole range of soluble carbohydrates normally used in bacteriology and also some others, found in grass or likely to occur in the rumen, which are not usually employed in fermentation tests.

\section{METHODS}

Source of rumen contents. For the bacterial counts, rumen contents $(c .100 \mathrm{ml}$.) were taken as required from hay-fed sheep no. 879 (previously used by Sugden \& Oxford, 1952) which had a closed permanent rumen fistula. Sampling by means of a wide-bore glass tube was usually carried out at 10 a.m., $2 \mathrm{hr}$. after feeding; the specimen in a closed flask was immediately placed in the incubator. For preparation of cleared rumen liquor for the basal medium, rumen contents (1 l. at a time) were withdrawn from any available fistulated sheep fed on meadow hay only, or the whole rumen contents of a slaughtered hay-fed sheep were worked up without loss of time. It is much more difficult, or impossible, to obtain a clear rumen liquor from sheep fed on concentrates as well as hay. Hence it has not yet been possible to study the rumen microflora of such sheep by these methods.

Preparation of a clear rumen liquor for use in the basal medium. The coarse plant particles were removed from rumen contents by straining through several layers of surgical gauze. The filtrate was put through a Sharples supercentrifuge, then filtered again through Seitz clarifying and sterilizing pads (Messrs J. C. Carlson Ltd., Ashton-under-Lyne, Lancs) in that order. If the liquor became alkaline at any stage, particularly before Seitz filtration, glacial acetic acid was carefully added to neutralize again. The clear goldenbrown liquid was finally stored in the cold room at $+2^{\circ}$ in sterilized screwcapped bottles 'medical flats'. This clarified rumen liquor would usually keep for a month without showing a precipitate or any sign of growth of microorganisms; as much as 2-3 1. per week could be prepared without difficulty.

Preparation of a nutrient agar containing the carbohydrate to be tested in cleared rumen liquor supplemented with amino-acids. As described later, viable counts were made in screw-capped 'Universal' bottles $(8 \times \mathbf{2 . 7} \mathrm{cm}$.) each containing about $12 \mathrm{ml}$. agar. They were chosen because they are cheap, sturdy and the solidified agar could easily be removed from them aseptically when required without breaking the bottle. The agar contained, per $12 \mathrm{ml} .: 5 \%$ casein hydrolysate solution (Allen and Hanbury, vitamin-free for microbiological assay), $2 \mathrm{ml}$., $0.5 \%$ DL-tryptophan solution, $0.5 \mathrm{ml}$.; $1.5 \%$ sugar solution, $1 \mathrm{ml}$.; $2 \%$ agar (neutral, Baird and Tatlock Ltd.) dissolved in cleared and 
buffered rumen liquor, $8.5 \mathrm{ml}$. Everything was sterilized by steaming, or where possible by Seitz filtration; nothing save glassware was autoclaved. The stock solutions of casein hydrolysate and tryptophan were sterilized by steaming, kept in the cold room and briefly re-steamed before use. A fresh lot of each was prepared every fortnight. The sugar solution was usually sterilized by Seitz filtration, otherwise, with more stable carbohydrates like starch and the sugar alcohols, by steaming.

In order to prevent any appreciable change of $\mathrm{pH}$ value during sterilization it was found advisable to buffer the cleared rumen liquor by the addition of $1 \mathrm{ml}$. phosphate solution/100 ml. cleared rumen liquor; the phosphate solution used contained $\mathrm{KH}_{2} \mathrm{PO}_{4}, 10 \mathrm{~g}$; $\mathrm{K}_{2} \mathrm{HPO}_{4}, 15 \mathrm{~g}$.; distilled water, $100 \mathrm{ml}$. It was also found to be absolutely necessary to add the extra amino-acids to the rumen liquor agar. Cleared rumen liquor itself (from hay-fed sheep) contained too little organic-N to promote quick growth of saccharolytic rumen bacteria.

Setting up the count. Three parallel sets of bottles were always incubated side by side, viz. (1) nutrient agar with the carbohydrate to be tested, (2) with mannitol as positive control, (3) without any added carbohydrate. About $250 \mathrm{ml}$. clear nutrient agar were required for each experiment. Each $1 \mathrm{oz}$. screw-capped bottle bore three scratch-marks corresponding to 10,12 , and $14 \mathrm{ml}$. contents respectively. Some twenty bottles were first sterilized empty on each occasion.

The requisite total amount of agar was melted in the buffered rumen liquor by careful heating over a wire gauze with an asbestos centre. The liquid was then strained through glass wool into another container in the steamer, and sterilized by steaming for $1 \mathrm{hr}$. on the first day, and $20 \mathrm{~min}$. on each of two succeeding days. The final stages of the last sterilization were carried out in a tall sterile beaker, nearly filled with the molten agar, which after steaming was allowed to cool in the steamer. Usually the dross which had accumulated during the three steamings readily sank to the bottom while the agar was still molten. The clear supernatant was then very carefully decanted into a sterile empty flask, a small portion removed for determination of $\mathrm{pH}$ value, and the rest (when bromothymol blue showed that the $\mathrm{pH}$ value was between 6 and 7 ) used immediately to fill the bottles to the $12 \mathrm{ml}$. mark in each instance. The bottles had previously been charged with the requisite amounts of sterile casein hydrolysate, tryptophan and the solution of the sugar to be tested (or mannitol solution or sterile water). After gentle shaking to effect mixing, the bottles were placed in a water-bath at $45^{\circ}$ until required.

The flask containing the rumen contents upon which the count was to be made was then vigorously shaken by hand and one or two standard drops (c. 50-60 mg.) were added from a sterile Pasteur pipette to $12 \mathrm{ml}$. of molten agar in one of the bottles containing extra amino-acids but no carbohydrate. After gentle shaking, $2 \mathrm{ml}$. were transferred by pouring, i.e. from the $12 \mathrm{ml}$. mark to the $10 \mathrm{ml}$. mark, to a second bottle. This second bottle, which now contained $14 \mathrm{ml}$. agar, was used to start the three series of dilutions: (1) with the carbohydrate to be tested (14 $\rightarrow 12 \mathrm{ml}$.); (2) with mannitol $(12 \rightarrow 10 \mathrm{ml}$.); (3) with no carbohydrate (10 ml. $\rightarrow 8 \mathrm{ml}$. by guesswork; nothing ever grew 
in 3 days in these ' no carbohydrate' controls). Each series was likewise carried on for four 7-fold dilutions in all, corresponding to dilutions of c. 1/10,000, $1 / 70,000,1 / 500,000$, and $1 / 3$ million, respectively, of the original rumen contents. Controls ( 1 bottle each) were also put up with nutrient agar with the carbohydrate, with mannitol, and with no carbohydrate at all, but without any rumen contents. Nothing ever grew in these uninoculated bottles. When the whole series had been put up in this way, all the bottles were quickly cooled in cold water till the agar had completely set. Each bottle was then completely filled with sterile water, the caps screwed down tightly and the whole incubated at $38^{\circ}$ for 4 days in all, colonies evident to the naked eye being counted daily. At the end the water was poured out completely (it usually contained sufficient bacterial growth to be turbid) and the solid agar plug bisected or trisected lengthwise with a sterile spatula. Each piece was then carefully fished out into a sterile dish for preparation of smears or pure culture isolations from individual colonies. Some trials with a sterile liquid paraffin layer above the agar, instead of water, gave trouble in the subsequent examination of individual colonies, because of tiny oil droplets. It was concluded that water was preferable to oil. Trials in which resazurin was incorporated in the agar showed that although the resazurin was not in the reduced state at the start of the incubation, as soon as growth occurred, either in the water above, or in the agar below, it was quickly decolorized. The depth of agar in each bottle was $c .3 \mathrm{~cm}$. Thus there would seem to be no reason why obligate anaerobes should not grow in the depths after a day or two, provided that facultative anerobes had begun to grow first of all. Trials in which extra S-containing reducing substances were incorporated in the nutrient agar are described below. The actual weight of rumen contents used in each count was determined by weighing 10 drops of rumen contents delivered by the same Pasteur pipette as used for inoculating the first bottle.

The counting of colonies before dissection of the agar was done with the bottle held in front of a strong light. Only when the agar was quite clear could all the colonies be counted. Hence the necessity for going to great trouble to ensure this, as previously described.

Carbohydrate substrates. Unless otherwise stated, carbohydrates incorporated in the nutrient rumen liquor and other agars were best quality commercial specimens supplied by L. Light and Co., or by Messrs T. Kerfoot (Biochemical Reagent Quality). Amylose was a specimen of purified potato amylose supplied by Dr P. N. Hobson; bacterial levan was the specimen used by Masson \& Oxford (1951); rumen holotrich 'starch' was the specimen prepared by these authors (1951). Both these last named carbohydrates may be regarded as possible substrates made by microbiological action in the rumen.

A soluble hemicellulose substrate was obtained from unbleached and untreated flour by aqueous extraction by the method of Perlin (1951). The cold water soluble fraction was purified by ethanol precipitation and the pure white powder so obtained dissolved in a little dilute caustic soda. The solution which was starch-free was diluted to the required carbohydrate concentration $(1.5 \%)$ cautiously neutralized with dilute $\mathrm{HCl}$, and sterilized by two brief 
steamings. According to Perlin pentoses are the chief constituent sugars of this complex, but we have not checked this with our product, save to show that it gave a strong pentose test with $\mathrm{HCl}$ and phloroglucinol. It contained some protein as well as polysaccharide.

Isolation of pure cultures from individual colonies developing below the surface of the agar in the counts. By means of a small loop portions of single colonies in the agar from the bottles were transferred to glucose peptone yeast extract broth, and incubated overnight (not longer, unless nothing grew). The liquid culture was then plated out, by streaking on the same medium solidified with agar. Usually only one kind of colony grew on each plate. Single colonies were then transferred to Robertson's cooked meat medium, and after incubation for $24 \mathrm{hr}$., the cultures were kept in the cold room until required. When it was desired to investigate them further, they were streaked on blood agar, and any plates obviously showing a mixed culture were discarded. Single colonies were then again picked off into Robertson's cooked meat medium. These served as stock cultures. For study of fermentation reactions, inoculations into the carbohydrate broths were made from a culture in nutrient heart broth. Other tests were made by direct inoculation from the cooked meat stock cultures.

It was always desirable to test an isolate in the simple rumen liquor basal agar used for the counting, in order to find out whether it would still grow in presence of the carbohydrate which had been used in the dilution series from which it had been isolated. Some of the isolates from the mannitol agars, for example, did not respond to this test. This may mean that the original colony which developed in the mannitol rumen liquor agar contained more than one bacterial species. There can be little doubt however that the actual culture isolated did originate from rumen contents; so no distinction is made at the moment on these grounds, since the main purpose of this paper is to survey, if possible, the whole facultatively anaerobic rumen population.

\section{RESULTS}

\section{Relative counts with various carbohydrate substrates}

Only colonies clearly visible to the naked eye, or by means of a $\times 3$ handlens were counted. Any background of microscopically small pin-point colonies was ignored. The count on mannitol was always small and of the order of $10^{6}$ organisms/g. rumen contents. The colonies on this mannitol-containing medium usually needed 3 days to reach a diameter of $c .1 \mathrm{~mm}$. Many simple sugars gave a very much larger count than did mannitol, the colonies developing in 1 or 2 days. Gas-forming colonies sometimes developed in the mannitol agar, but very rarely on any other carbohydrate. The small compact streptococcal colonies were easily distinguished from others much larger and diffuse in outline and which usually yielded Gram-negative rods. Table 1 summarizes the counts obtained with several carbohydrates and also gelatin, as substrates.

It was always found that the colonies seemed to be evenly distributed throughout the agar. With those sugars which gave a count of the order of 
$10^{8}$ organisms/g. rumen liquor, both the 5 th and the 6 th dilutions were counted (if possible) and equal weight given to each. Usually the 5th bottle contained between 5 and 15 times as many colonies as the 6th. Whenever a large count was obtained, the colonies in the 6th bottle were all, or almost all, Grampositive cocci.

Table 1. Viable counts of facultatively anaerobic bacteria in the rumen liquor capable of fermenting various carbohydrates

\begin{tabular}{|c|}
\hline $\begin{array}{l}\text { Period of } \\
\text { incubation of } \\
\text { carbohydrate } \\
\text { agar } \\
\text { (days) }\end{array}$ \\
\hline 4 \\
\hline 4 \\
\hline 2 \\
\hline $\mathbf{3}$ \\
\hline 3 \\
\hline 2 \\
\hline 1 \\
\hline $\mathbf{3}$ \\
\hline 4 \\
\hline 1 \\
\hline 2 \\
\hline$\overline{2}$ \\
\hline$\overline{2}$ \\
\hline$\overline{1}$ \\
\hline 4 \\
\hline 2 \\
\hline 1 \\
\hline 3 \\
\hline 7 \\
\hline
\end{tabular}

Carbohydrate tested
amylose
arabinose
cellobiose
dulcitol
galactose
glucose
inulin
lactose
levan (bacterial)
maltose
soluble flour hemicellulose
raffinose
rhamnose
salicin
sorbitol
starch (holotrich)
sucrose
xylose
gelatin

No. of colonies developing (millions/g. rumen contents)

\begin{tabular}{|c|c|c|}
\hline & & incubation \\
\hline $\begin{array}{c}\text { In } \\
\text { carbohydrate } \\
\text { agar }\end{array}$ & $\underset{\substack{\text { In } \\
\text { mannitol }}}{\text { agar }}$ & $\begin{array}{l}\text { mannitol } \\
\text { agar } \\
\text { (days) }\end{array}$ \\
\hline 187 & $<1$ & $\mathbf{3}$ \\
\hline 7 & 1.5 & 4 \\
\hline 176 & $<1$ & 2 \\
\hline$<1$ & $<1$ & 3 \\
\hline 16 & 2 & 3 \\
\hline 97 & $<1$ & $\mathbf{3}$ \\
\hline 184 & $<1$ & 2 \\
\hline $\mathbf{3 0}$ & $<1$ & $\mathbf{3}$ \\
\hline 50 & $\mathbf{2 \cdot 5}$ & $\mathbf{3}$ \\
\hline 250 & $<1$ & $\mathbf{3}$ \\
\hline $\mathbf{5 3}$ & - & - \\
\hline 120 & $<1$ & 2 \\
\hline 2 & 1.5 & 2 \\
\hline 464 & $<1$ & 3 \\
\hline 11 & $<1$ & 2 \\
\hline 81 & $<1$ & 2 \\
\hline 76 & 2 & $\mathbf{3}$ \\
\hline 14 & 3 & $\mathbf{3}$ \\
\hline o & $<1$ & 3 \\
\hline
\end{tabular}

\section{Pure cultures isolated from the counting bottles}

A large number of representative isolates were obtained in pure culture, and included 142 strains of streptococci. Table 2 gives a picture of the relationship between carbohydrate fermented and the kind of bacteria which developed. The streptococcal isolates from sugars other than mannitol usually fermented starch, but not mannitol; only a small proportion of them had the characteristics of Strep. faecalis. A complete description of these and other isolates will be given in a later paper. It may be mentioned here that for a 'fodder control' the hay fed to the sheep was finely chopped and incubated with clear and sterile rumen liquor ( 5 parts) for 1-2 $\mathrm{hr}$. at $37^{\circ}$ and the resulting 'artificial' rumen contents, after vigorous shaking, was counted in the usual way, raffinose and mannitol being the substrates. In each case the count was of the order of $10^{6}$ organisms/g., mostly consisting of Gram-negative rods. The Gram-positive cocci, which developed when genuine rumen contents were counted in raffinose agar (see Table 2) were not in evidence. It cannot yet be stated with certainty whether or not the Gram-negative rods obtained from 'genuine' and from 'artificial' rumen contents are similar. 
Table 2. List of kinds of bacteria actually isolated in pure culture in the viable counts carried out with rumen contents at various dilutions in carbohydrate agars

(Dilutions : $\left.a=1 / 10^{4} ; b=1 / 70,000 ; c=1 / 500,000 ; d=1 / 3,000,000\right)$

Total no. of strains isolated in pure culture at various dilutions

\begin{tabular}{|c|c|c|c|}
\hline $\begin{array}{l}\text { Carbohydrate } \\
\text { added to agar } \\
\text { for the count }\end{array}$ & $\begin{array}{c}\text { Coliform } \\
\text { bacteria* }\end{array}$ & Streptococci & $\begin{array}{l}\text { Other bacteria isolated in } \\
\text { pure culture from } \\
\text { dilutions } a, b \text { or } c\end{array}$ \\
\hline Mannitol & Mostly $(a+b)=100$ & Mostly $(a+b)=63$ & $\begin{array}{l}\text { Other Gram-positive cocci : } 12 \\
\text { Gram-negative cocci : } 3 \\
\text { Gram-positive rods : } 4\end{array}$ \\
\hline Galactose & $d=0$ & $d=5$ & $\mathbf{0}$ \\
\hline Sucrose & $d=0$ & $d=11$ & Tetracoccus : 1 \\
\hline Lactose & $d=0$ & $d=6$ & $\mathbf{0}$ \\
\hline Maltose & $d=0$ & $d=19$ & $\mathbf{0}$ \\
\hline Rhamnose & $b=12$ & $b=0$ & $\mathbf{0}$ \\
\hline Salicin & $d=0$ & $d=19$ & Other Gram-positive cocci : 2 \\
\hline Xylose & $a=\mathbf{3 0}$ & $a=2$ & $\begin{array}{l}\text { Gram-negative cocci : } 9 \\
\text { Other Gram-positive cocci : } 2\end{array}$ \\
\hline Inulin & $d=0$ & $d=1$ & Other Gram-negative rods $\dagger$ : 5 \\
\hline Raffinose & $d=0$ & $d=6$ & $\begin{array}{l}\text { Other Gram-positive cocci : } 4 \\
\text { Other Gram-negative rods } \uparrow: 10\end{array}$ \\
\hline $\begin{array}{l}\text { Amylose } \\
\text { Levan (bacterial) } \\
\text { Sorbitol }\end{array}$ & $\begin{array}{c}d=0 \\
(b+c)=0 \\
a=12\end{array}$ & $\begin{array}{c}d=6 \\
(b+c)=4 \\
a=0\end{array}$ & Other Gram-negative rodst : 1 \\
\hline Sorbitol & $a=12$ & $a=0$ & $\mathbf{0}$ \\
\hline
\end{tabular}

\section{Effect of addition of reducing substances to the basal rumen liquor agar}

The effects of the following additions were tested: $\mathrm{Na}_{2} \mathrm{~S}(0.02 \%)$; cysteine hydrochloride (exactly as recommended by Huhtanen et al. 1952); $\mathrm{Na}$ mercaptoacetate (thioglycollate; $0.002 \mathrm{M}$ ). In no case did an appreciably larger number of visible colonies develop than in the bottles without the reducing supplement. The mercaptoacetate at the concentration used seemed to be slightly toxic in that the colonies (with glucose as carbohydrate substrate) took longer to develop, although the final count was the same. Incubation of the bottles in an anaerobic jar likewise had no great effect, save in increasing the 'background' of microscopically small colonies developing during 3 days' incubation.

\section{DISCUSSION}

In the main these results confirm the studies of MacPherson (1953) who found a facultatively anaerobic streptococcal population in the sheep's rumen with fermentation reactions similar to those of Streptococcus bovis. In view of the experience of previous investigators, it is not clear to us why the addition of reducing substances had so little effect on our viable counts, when a basal agar was used which so nearly resembled rumen liquor itself. Our technique would not, however, count all viable saccharolytic bacteria which need a definite concentration of bicarbonate ions in the medium as well as reducing conditions 
before growth can occur at all. Opinions may differ on what the order of magnitude of the total viable bacterial population of the rumen of a hay-fed sheep really is. In view of the rather small protein content of the uncleared rumen liquor of sheep fed on meadow hay (c. 3.5 mg./g.; McDonald, 1952) it would seem best to adopt for the moment the smallest total count so far reported for that fluid (1-2 $\times 10^{9}$ organisms/ml.) by Louw \& Van der Wath (1943) (although their sheep was admittedly fed on a poor quality veldt hay), rather than the very much higher totals, reported for sheep rather differently fed, by Australian and American workers. Granting this, the population of $c .10^{8} / \mathrm{g}$. which we find for facultatively anaerobic bacteria capable of fermenting certain soluble carbohydrates (e.g. glucose, maltose, cellobiose, salicin among others in Table 1 ), is clearly not a negligibly small part of the total viable rumen population. This in turn must necessarily be rather less than the total count. Since streptococci and coliform bacteria, as well as clostridia, flourish in the caecum and large intestine of many animals, there can of course be no $a$ priori reason why facultatively anaerobic bacteria should not be present and active in large numbers in the rumen. Preoccupation with cellulose fermentation in that site, which undoubtedly is an anaerobic process, may have blinded some investigators to the fact that many other fodder carbohydrates, including soluble ones like sucrose and grass levans are necessarily often fermented in large amounts in the rumen, and that there is no reason at all to suppose that these other carbohydrate fermentations are brought about in the main by obligatory anaerobic bacteria. The rumen cellulolytic anaerobes, according to Hungate (1950), would certainly not ferment them. Even when the fodder consists entirely of hay, which contains very little truly soluble carbohydrate, there is, as our results show, a not inconsiderable facultatively anaerobic and saccharolytic bacterial population in the sheep's rumen. It would be strange indeed if, when the fodder consists chiefly of soluble substances, e.g. spring grass, the facultatively anaerobic population were not of greater density still. If it should prove possible to obtain a clear rumen liquor in such instances, the supplementation by amino-acids, as in the present work, might not be necessary since the concentration of organic-N would be much greater than in rumen contents from hay-fed sheep (cf. McDonald, 1952).

\section{REFERENCES}

Heald, P. J. (1952a). The fermentation of pentoses and uronic acids by bacteria from the rumen contents of sheep. Biochem. J. 50, 503.

Heasd, P. J. (1952b). The metabolism of glucuronic acid by xylose-fermenting coliform bacteria. Biochem. J. 52, 378.

Heatd, P. J. \& Oxford, A. E. (1953). Fermentation of soluble sugars by anaerobic holotrich ciliate protozoa of the genera Isotricha and Dasytricha. Biochem. J. $53,506$.

Huhtanen, C. N., Rogers, M. R. \& Gall, L. S. (1952). Improved techniques for isolating and purifying rumen organisms. J. Bact. 64, 17.

Hungate, R. E. (1950). The anaerobic mesophilic cellulolytic bacteria. Bact. Rev. $14,1$. 
Louw, J. G. \& vaN Der Wath, J. G. (1943). The influence of varying maize supplements on the digestibility of the cellulose in a poor veld hay in relation to bacterial population of the rumen of sheep with a note on the nitrogen metabolism. Onderstepoort J. vet. Sci. 18, 177.

MacPherson, M. J. (1953). The isolation and identification of amylolytic streptococci from the sheep's rumen. J. Path. Bact. 66, 95.

Masson, F. M. \& OxFord, A. E. (1951). The action of ciliates of the sheep's rumen upon various water-soluble carbohydrates including polysaccharides. J. gen. Microbiol. 5, 664.

McDonald, I. W. (1952). The role of ammonia in ruminal digestion of protein. Biochem. J. 51, 86.

Perlin, A. S. (1951). Isolation and composition of the soluble pentosans of wheat flour. Cereal Chem. 28, 370.

Sijpesteisn, A. K. \& Elsden, S. R. (1952). The metabolism of succinic acid in the rumen of the sheep. Biochem. J. 52, 41.

Sugden, B. \& Oxford, A. E. (1952). Some cultural studies with holotrich ciliate protozoa of the sheep's rumen. J. gen. Microbiol. 7, 145.

(Received 2 March 1953) 